BMC

Genomics

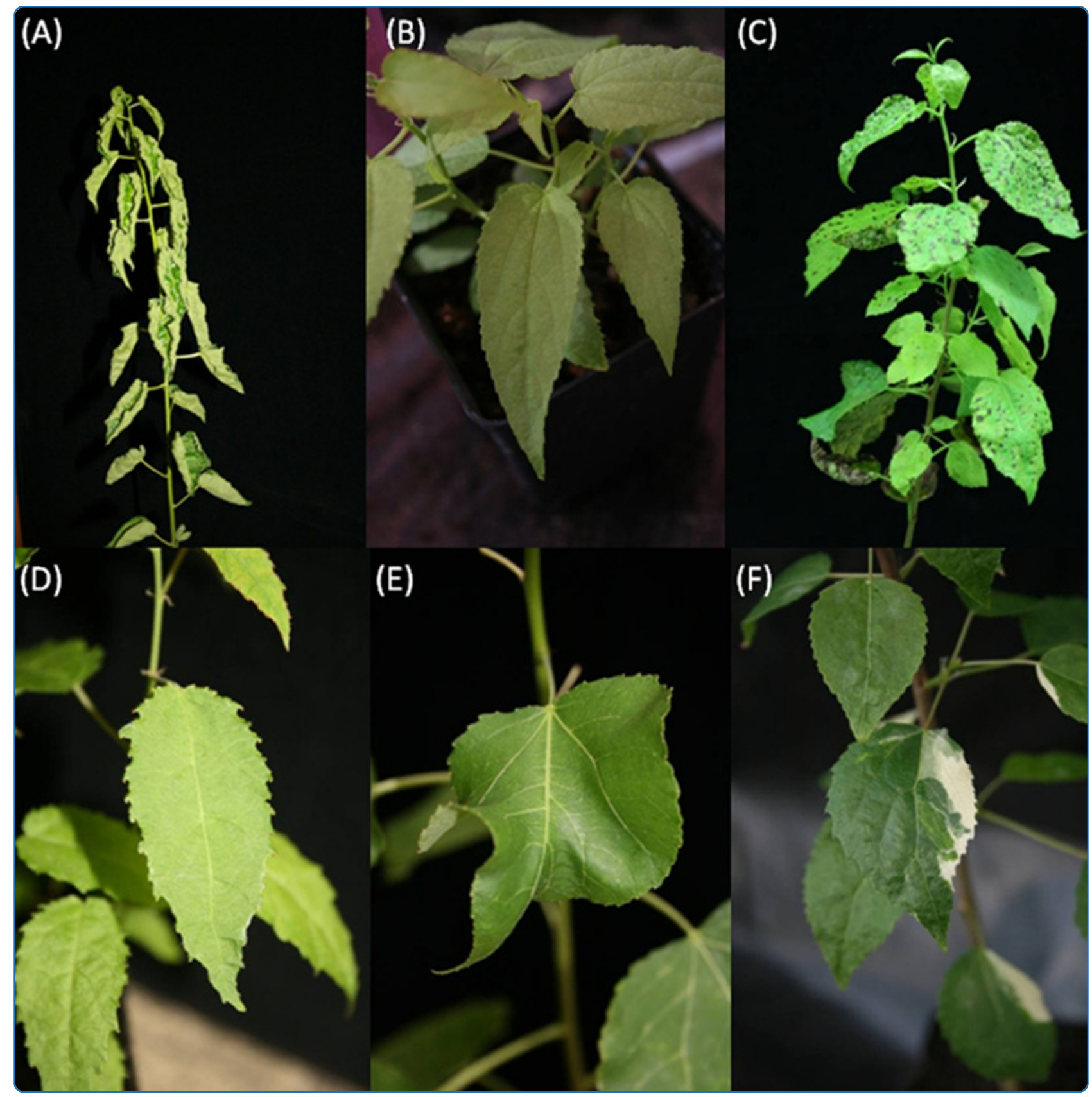

Ac/Ds-transposon activation tagging in poplar: a powerful tool for gene discovery

Fladung and Polak

C Biomed Central

Fladung and Polak BMC Genomics 2012, 13:61

http://www.biomedcentral.com/1471-2164/13/61 (6 February 2012) 


\title{
Ac/Ds-transposon activation tagging in poplar: a powerful tool for gene discovery
}

Matthias Fladung ${ }^{*}$ and Olaf Polak

\begin{abstract}
Background: Rapid improvements in the development of new sequencing technologies have led to the availability of genome sequences of more than 300 organisms today. Thanks to bioinformatic analyses, prediction of gene models and protein-coding transcripts has become feasible. Various reverse and forward genetics strategies have been followed to determine the functions of these gene models and regulatory sequences. Using T-DNA or transposons as tags, significant progress has been made by using "Knock-in" approaches ("gain-offunction" or "activation tagging") in different plant species but not in perennial plants species, e.g. long-lived trees. Here, large scale gene tagging resources are still lacking.

Results: We describe the first application of an inducible transposon-based activation tagging system for a perennial plant species, as example a poplar hybrid (P. tremula L. $\times$ P. tremuloides Michx.). Four activation-tagged populations comprising a total of 12,083 individuals derived from 23 independent "Activation Tagging Ds" (ATDs) transgenic lines were produced and phenotyped. To date, 29 putative variants have been isolated and new ATDs genomic positions were successfully determined for 24 of those. Sequences obtained were blasted against the publicly available genome sequence of $P$. trichocarpa v2.0 (Phytozome v7.0; http://www.phytozome.net/poplar) revealing possible transcripts for 17 variants.

In a second approach, 300 randomly selected individuals without any obvious phenotypic alterations were screened for ATDs excision. For one third of those transposition of ATDs was confirmed and in about $5 \%$ of these cases genes were tagged.

Conclusions: The novel strategy of first genotyping and then phenotyping a tagging population as proposed here is, in particular, applicable for long-lived, difficult to transform plant species. We could demonstrate the power of the ATDs transposon approach and the simplicity to induce ATDs transposition in vitro. Since a transposon is able to pass chromosomal boundaries, only very few primary transposon-carrying transgenic lines are required for the establishment of large transposon tagging populations. In contrast to T-DNA-based activation tagging, which is plagued by a lack of transformation efficiency and its time consuming nature, this for the first time, makes it feasible one day to tag (similarly to Arabidopsis) every gene within a perennial plant genome.
\end{abstract}

Keywords: functional genomics, Populus, mutant, tree genomics, transgenic aspen, transposition

\section{Background}

One of the global challenges for the next decades is the reproducible and sustainable production of wood to meet the increasing demand for energy and solid raw material. The majority of the terrestrial biomass is produced by forest trees, which are grown either in natural (primeval and secondary) forests or, with increasing

\footnotetext{
* Correspondence: matthias.fladung@vti.bund.de

Johann Heinrich von Thuenen-Institute Federal Research Institute for Rural Areas, Forestry and Fisheries Institute of Forest Genetics Sieker Landstr. 2 D22927 Grosshansdorf Germany
}

(ㄷ) 2012 Fladung and Polak; licensee BioMed Central Ltd. This is an Open Access article distributed under the terms of the Creative Commons Attribution License (http://creativecommons.org/licenses/by/2.0), which permits unrestricted use, distribution, and reproduction in any medium, provided the original work is properly cited. significance, in tree plantations. Plantation forestry is predicted to become even more important in the future to reduce the pressure on primeval forests in an effort to support ecologically sustainable and economically profitable wood production. One substantial opportunity for plantation forestry lies in the ability to use improved domesticated tree varieties or even genetically modified (GM) trees, specifically designed for a respective enduse, e.g. low-lignin trees for pulp and paper or saccharification (bioethanol production), or high-lignin trees for solid wood combustion.

\section{Biomed Central}


Improving trees by conventional breeding is time-consuming and often not cost-effective due to the long vegetative periods and long reproduction cycles [1]. The availability of whole genome sequences of forest trees offers the opportunity to detect novel genes responsible for important developmental processes like tree growth or wood production. In combination with the publicly accessible whole genome sequences for Populus trichocarpa [2] and Eucalyptus grandis (http://eucalyptusdb.bi. up.ac.za/), the development of new genomic tools like "Target Induced Local Lesions IN Genomes" (TILLING, [3]) or the production of genotypes carrying novel (desired) gene combinations offer the opportunity to fasten tree domestication.

The $P$. trichocarpa genome is approximately $403 \mathrm{Mb}$ in size, arranged in 19 chromosomes and assembled into 2,518 scaffolds. The number of loci containing protein-coding transcripts is 40,668 , but 45,033 proteincoding transcripts have been detected (annotation v2.2 of assembly v2.0; Phytozome v7.0; http://www.phytozome.net/poplar). However, only for a minority of these loci the functions of the protein-coding transcripts are positively known. For tree species including poplar, only very few mutants have been described that could be used to analyse specific gene function behind the mutation [4]. Induced mutagenesis combined with phenotyping tools offer significant opportunities for linking gene models with putative functions. Over the past decade, genomics reagents have become available to produce a wealth of tagged mutant plants in particular for annual model species. Mutant induction in such annual plants by T-DNA insertion or using the mobility of transposable elements (e.g. the maize $A c$ element or its inactive derivate Ds) in most cases was achieved using knockout tagging, disrupting a functional pathway by element insertion in functional genes and subsequent selfing of mutagenized plants. In Arabidopsis, it is now possible to acquire a mutant of nearly every gene model by using publicly available populations of T-DNA [5,6] or transposon $[7,8]$ insertional mutagenesis lines. Similarly, large scale gene tagging resources have been developed for rice $[9,10])$ and barley $[11,12]$.

The use of loss-of-function mutations described above is not well suited for application in long-living trees. In contrast, gain-of-function strategies have significant advantages because affected genes are not disrupted but activated [13-15]. One gain-of-function approach is "Activation tagging" which means the up-regulation of an endogenous gene through presence of a tag containing strong enhancers [16] or promoters facing outwards $[17,18]$. The concept behind transformation-based activation tagging is that the enhancers or the promoter are located on the T-DNA (or the transposon), and following insertion of the T-DNA close to a gene, its transcription will be activated. For Arabidopsis, large sets of "activation tagging populations" have been generated containing several T-DNA-based activation tagging vectors which are readily available from insertion collections and stock centers $[19,20]$.

Despite the publication of some promising reports that describe the creation of T-DNA-based activationtagged populations in poplar $[15,21]$ and the identification of GA2-OXIDASE, a dominant gibberellin catabolism gene, as the first gene to be isolated from such a population [22], efficient gene tagging system for long lived forest tree species are still wanting. In order to fill this gap, Fladung et al [13] and Kumar and Fladung [23] proposed the use of a transposon-based activation tagging system for poplar. This proposal was based on the fact that the maize transposable element $A c$ is functional in the Populus genome [24], and re-integrations occur at high frequencies in or near coding regions [23]. Further, the majority of re-integrations were found scattered over many unlinked sites on other scaffolds than the one carrying the original integration locus, confirming that $A c$ does in fact cross chromosome boundaries in poplar [25].

In this paper, we describe for the first time the development of an efficient activation tagging system for aspen-Populus based on a non-autonomous "Activation Tagging Ds" (ATDs) system as described by Suzuki et al [26], in combination with a heat-inducible Ac-transposase. Four activation-tagged populations comprising in total 12,083 individuals have been produced and phenotyped. Many of the phenotypes have not been described before. Molecular analyses of individuals of the mutant population confirm the excision of the ATDs element from the original insertion locus and re-integration into or close to a gene locus, with unknown function in many cases. In a second, "blind" approach (without any phenotypic selection), 300 randomly selected individuals were PCR-screened for ATDs excision. In approximately one third of the investigated individuals, ATDs transposition was confirmed and analyses of the new genomic positions of ATDs reveal a very high percentage of tagged genes.

This system might prove particularly useful not only in poplar but also in other long-lived forest and fruit tree species where T-DNA-based activation tagging systems are not reliable due to the lack of high-efficiency transformation protocols.

\section{Results}

\section{Production of transgenic plants and molecular analysis}

From the seven independent HSP::TRANSPOSASE transgenic lines obtained, two transgenic lines, N66-2 and N66-5, were selected for super-transformation with p7N-ATDs-rolC guided by the results of PCR (presence 
of construct) and RT-PCR experiments (highest transposase transcript abundance; data not shown). Both lines were shown to carry one copy of the HSP::TRANSPO$S A S E$ gene (Table 1). The genomic insertion loci were identified on scaffold 3 at positions 16,990,223 and 15,414,366 for line N66-2 and N66-5, respectively (Table 1). Both insertion loci sequences showed high similarities to $P$. trichocarpa transcripts, for N66-2 to POPTR_0003s17690 with no functional annotation, and for N66-5 to POPTR_0003s15650 with functional annotation to CTP synthase (UTP-ammonia lyase) (Table 1).

Super-transformation of N66-2 and N66-5 with p7NATDs-rolC yielded 23 double transgenic lines (twelve for N66-2 and eleven for N66-5) carrying the ATDsrolC gene construct (data not shown). Using Southern blot analyses, the copy number of the ATDs-rolC gene could be determined for 21 double transgenic lines: 16 carried one copy, 4 lines two copies, and 1 line four copies (Table 2). Figure 1 shows a representative Southern blot with ScaI restricted and nptII-probed DNA isolated from eleven transgenic lines from the N82 group.

In 20 double transgenic lines, genomic sequences flanking the insertion locus of the second T-DNA could be successfully located on 13 different scaffolds, although in 3 one-copy lines and in 2 two-copy lines evalues were only marginal (bold in Table 2). For BLAST-analyses that resulted in more than one hit, either the hit with lower e-value was considered, or when similar e-values were obtained, both hits are shown in Table 2. Three of four ATDs copies from line N82-7 could be positioned in the genome, one with low, one with intermediate and one with a high e-value (Table 2). Genomic sequences from ten of the 20 lines showing successful T-DNA insertion allowed positive transcript annotation (Table 2).

All aspen-specific sequences obtained in this study were integrated into GabiPD database (http://www. gabipd.org) and submitted to GenBank ([GenBank: JM973488] to [GenBank:JM973566]).

Heat shock experiments and ATDs excision

To induce ATDs transposition, four different heat shock experiments were conducted using a total of 23 independent double transgenic HSP::TRANSPOSASE/ ATDs aspen lines (Table 3). Following the heat shock, plant material was crushed into pieces as small as possible and transferred to hormone-containing medium to regenerate shoots (Figure 2). Successfully regenerated shoots were cut, transferred to WPM medium without hormones for rooting, and rooted plants were phenotyped in tissue culture or in soil after three to six months growth in the greenhouse.

To confirm that the PCR fragment generated with the primer pair $16 / 37$ contains the ATDs empty donor site, PCR fragments from 18 plants deemed to be positive for ATDs excision were sequenced. All sequences revealed the typical -GCCG- or -GGCG- linkage sequence between the $n p t-I I-\mathrm{T} 35 \mathrm{~S}$ and the rolC fragments, thus clearly indicating ATDs excision (data not shown).

\section{Phenotyping in four tagging populations}

In total, 12,083 plants from 23 different ATDs transgenic lines were screened for phenotypic variation, mainly growth deficiency, chlorophyll abnormalities, and alterations in leaf form and shape. Twenty nine different phenotypic variants were detected, most of them remaining stable at least 12 month in tissue culture and/or in the greenhouse, as well as in copies generated by cuttings. Some phenotypes disappeared following the first winter period (data not shown) even if the ATDs insertion locus remained unchanged. A summary of detected phenotypes as well BLAST - and annotation results of new ATDs flanking sequences is presented in Table 4. Examples of pronounced phenotypes are shown in Figure 3.

So far, a new ATDs genomic position could be successfully determined for 24 out of the 29 different putative variants. Sequences for those were blasted against the publicly available genome sequence of $P$. trichocarpa v2.0 (Phytozome v7.0; http://www.phytozome.net/ poplar). Resulting e-values ranged from $\mathrm{e}^{-25}$ down to zero. Possible transcripts against $P$. trichocarpa could be annotated for 17 variants. For six lines, putative proteins were of unknown function or no functional annotation was possible (Table 4).

Table 1 Copy number of HSP::TRANSPOSASE in the single transgenic lines, and genomic insertion locus (scaffold and position) with score, e-value and, if applicable, annotated transcript.

\begin{tabular}{cccccc}
\hline $\begin{array}{c}\text { Transgenic } \\
\text { line }\end{array}$ & $\begin{array}{c}\text { Copy } \\
\text { number }\end{array}$ & $\begin{array}{c}\text { Genomic insertion locus (scaffold: } \\
\text { position)* }\end{array}$ & Score & $\begin{array}{c}\text { E- } \\
\text { value }\end{array}$ & Transcript \\
\hline N66-2 & 1 & $3: 16,990,223$ & 1132.0 & 0 & POPTR_0003s17690 (no functional annotation) \\
\hline N66-5 & 1 & $3: 15,414,346$ & 1222.2 & 0 & POPTR_0003s15650 CTP synthase (UTP-ammonia \\
lyase)
\end{tabular}

*based on BLAST-results against the genome sequence of $P$. trichocarpa v2.0 (Phytozome v7.0; http://www.phytozome.net/poplar). Successful positioning of blasted sequence on the physical map of $P$. trichocarpa was assigned to the Populus-aspen genome because of the high collinearity between the $P$. trichocarpa and $P$. tremula/P. tremuloides genomes [49]. 
Table 2 Copy number of ATDs-rolC in the double transgenic lines, and genomic insertion locus (scaffold and position) with score, e-value and, if applicable, annotated transcript.

\begin{tabular}{|c|c|c|c|c|c|}
\hline Transgenic line & Copy number & Genomic insertion locus (scaffold:position)* & Score & E-value & Transcript (POPTR_) \\
\hline N82-2 & 1 & $18: 5,952,389$ & 841.7 & 0 & - \\
\hline N82-3 & 1 & $7: 3,347,471$ & 854.3 & 0 & $\begin{array}{l}\text { 0007s05190 } \\
\text { no functional annotation }\end{array}$ \\
\hline N82-4 & 1 & $8: 2,414,980$ & 580.2 & $5.0 e-164$ & $\begin{array}{l}\text { 0008s04320 } \\
\text { Cyclin, N-terminal domain }\end{array}$ \\
\hline \multirow[t]{2}{*}{ N82-5 } & 1 & $607: 11,508$ & 132.9 & $1.4 \mathrm{e}-29$ & $\begin{array}{l}0607500230 \\
\text { no functional annotation }\end{array}$ \\
\hline & & $18: 4,994,998$ & 165.4 & $1.7 \mathrm{e}-39$ & $\begin{array}{l}\text { 0018s05440 } \\
\text { Ankyrin Repeat-Containing }\end{array}$ \\
\hline \multirow[t]{3}{*}{ N82-7 } & 4 & $7: 9,643,105$ & 71.6 & $2.5 e-11$ & - \\
\hline & & $2: 14,852,606$ & 41.0 & $2.2 \mathrm{e}-2$ & - \\
\hline & & n.d. ${ }^{* *}$ & & & \\
\hline \multirow[t]{3}{*}{ N82-8 } & 1 & $18: 1,568,406$ & 1463.8 & 0 & POPTR_0018s01710 \\
\hline & & or & & & F-Box/Leucine Rich Repeat Protein \\
\hline & & $3: 13,577,759$ & 1551.2 & 0 & POPTR_0003s13180 Heat Shock Protein 90 \\
\hline \multirow[t]{2}{*}{ N82-10 } & 2 & $2: 10,740,018$ & 612.2 & $5.3 e-174$ & $\begin{array}{l}0002 s 14460 \\
\text { Zinc-finger double stranded }\end{array}$ \\
\hline & & $5: 9,290,567$ & 91.5 & $3.4 \mathrm{e}-17$ & $\begin{array}{l}0005 s 12520 \\
\text { GRAS family transcription factor }\end{array}$ \\
\hline N82-11 & 1 & $16: 13,606,858$ & 879.5 & 0 & $\begin{array}{l}\text { POPTR_0016s } 14360 \\
\text { Elongation factor P, C-terminal }\end{array}$ \\
\hline \multirow[t]{2}{*}{ N82-12 } & 2 & $17: 7,632,882$ & 44.6 & $9.8 \mathrm{e}-3$ & - \\
\hline & & n.d.** & & & - \\
\hline \multirow[t]{2}{*}{ N82-14 } & 2 & $3: 13,408,914$ & 322.3 & $1.9 e-89$ & - \\
\hline & & n.d. ${ }^{* *}$ & & & - \\
\hline N82-15 & 1 & $2: 21,183,733$ & 199.7 & $6.8 \mathrm{e}-50$ & - \\
\hline N92-1 & 1 & $15: 6,453,477$ & 286.2 & $1.6 \mathrm{e}-75$ & - \\
\hline N92-2 & 1 & $2: 10,740,357$ & 706.4 & 0 & - \\
\hline N92-3 & 1 & $11: 16,469,472$ & 39.2 & $2.0 \mathrm{e}-3$ & POPTR_0011s13850 (COBRA-like protein) \\
\hline N92-4 & 1 & $10: 15,737,708$ & 515.2 & $2.1 e-144$ & - \\
\hline N92-5 & 1 & $10: 19,481,904$ & 417.9 & $4.4 \mathrm{e}-115$ & - \\
\hline N92-6 & n.d. ${ }^{* *}$ & n.d.* & & & \\
\hline N95-1 & 1 & n.d.** & & & \\
\hline \multirow[t]{2}{*}{ N95-2 } & 2 & $25: 155,725$ & 1490.9 & 0 & POPTR_0025s00400 (CYTH domain) \\
\hline & & $15: 824,499$ & 48.2 & $4.2 \mathrm{e}-4$ & - \\
\hline N95-3 & 1 & $9: 9,143,423$ & 291.6 & $3.0 \mathrm{e}-77$ & POPTR_0009s10720 (Arylacetamide deacetylase) \\
\hline N95-4 & 1 & $17: 7,632,882$ & 44.6 & $3.2 \mathrm{e}-3$ & - \\
\hline N95-5 & 1 & $16: 7,726,062$ & 562.1 & $1.4 \mathrm{e}-158$ & - \\
\hline N95-6 & n.d.** & n.d. ${ }^{* *}$ & & & \\
\hline
\end{tabular}

In bold: blast-results with high e-values. In BLAST-analyses where more than one hit was given, either the one with lower e-value or when similar, both hits are shown.

*based on BLAST-results against the genome sequence of $P$. trichocarpa v2.0 (Phytozome v7.0; http://www.phytozome.net/poplar). Successful positioning of blasted sequence on the physical map of $P$. trichocarpa was assigned to the Populus-aspen genome because of the high collinearity between the $P$. trichocarpa and P. tremula/P.tremuloides genomes [49].

${ }^{* *}$ n.d. $=$ not determined.

Suitability of the proof-of-concept approach for large scale transposon tagging in poplar

Randomly selected 300 greenhouse-grown plants without any obvious phenotypic alterations from 16 different double transgenic HSP::TRANSPOSASE/ATDs aspen were PCR-screened for ATDs excision by amplifying a $1,800 \mathrm{bp}$ long region spanning from the $n p t-I I$ to the rolC gene using the 16/37 primer pair (Figure 4 ). The number of tested plants per line varied from 10 to 26. Only in three lines (N92-3, N95-4, N95-5), no ATDs 


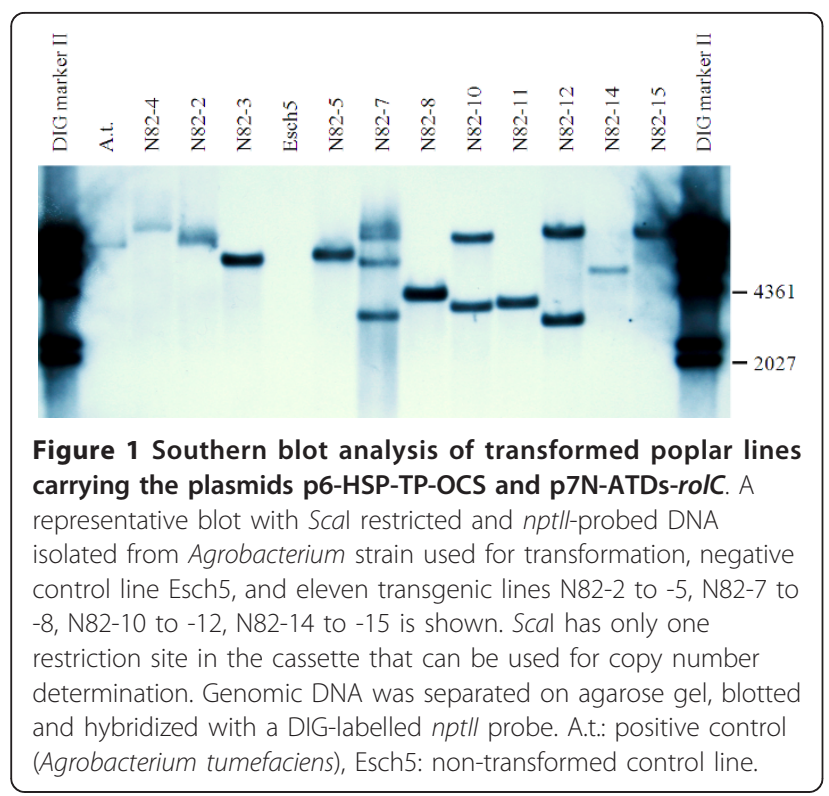

excision could be detected, and in each of N95-1 and N95-2, only two plants were detected (Table 5). Overall, just under one-third of the 300 plants analyzed revealed ATDs excision.

In order to determine new insertion loci, TAIL-PCR and sequencing was performed in plants that tested positive for ATDs insertion. Resulting sequences were blasted against the publicly available genome sequence of P. trichocarpa v2.0 (Phytozome v7.0; http://www.phytozome.net/poplar). In 26 plants (8.7\%) from eight lines, TAIL-PCR was successfully conducted and positive BLAST hits were obtained. ATDs flanking genomic sequences could be positively annotated to putative $P$. trichocarpa transcripts for 15 plants (5.0\%) belonging to six lines (N82-5, -14, -15, N92-1, N95-3, -6) (Table 5). Out of these, individuals from lines N82-5, N82-15, and N92-1 alone (bold in Table 5) accounted for 13 transcript annotations. A summary of BLAST- and annotation results of the new ATDs flanking sequences is given in Table 6. E-values of hits ranged from $\mathrm{e}^{-17}$ down to zero with exception of three high e-values in N825\#82, N82-5\#213, and N82-15 \#4.

\section{Discussion}

Different mutagenesis approaches based on heterologous (transferred) transposon element systems have been successfully applied in many plant species. Most prominently, the two element maize $A c /$ Ds system has been successfully used to generate insertional mutants in Arabidopsis, rice or barley [12,27-31]). In order to establish a similar transposon tagging system for trees, Fladung and Ahuja [24] transferred the autonomous Ac element to aspen-Populus and for the first time confirmed that $A c$ is functionally active in this tree species. Molecular evidence for $A c$ excision and re-integration into the genome was later provided by Kumar and Fladung [23]. Further, these authors showed that the majority of $A c$ genomic re-integration sites were found within or near coding regions. More recently, Fladung [25] analyzed in detail the genomic positions of $A c$ re-integrations by blasting $A c$-flanking aspen sequences against the publicly available genome sequence of $P$. trichocarpa v2.0 (Phytozome v7.0; http://www.phytozome.net/poplar). The majority of re-integrations were found scattered over many unlinked sites on different scaffolds confirming that in poplar $A c$ is able to cross chromosome boundaries. These latest results confirmed the feasibility of the approach first suggested by Kumar and Fladung [23] to use the $A c /$ Ds transposon tagging system for functional genomics studies in forest tree species, and in particular, for an efficient induction of mutants.

In this study, we took advantage of the already available "Activation Tagging Ds" system (ATDs) developed by Suzuki et al [26] that contains outwards directed 35S promoters at both ends. For our study, this ATDs system was combined with the phenotypic selectable marker gene rolC [23,32], which was cloned outside of the ATDs element so that it is active when ATDs is not

Table 3 Heat shock treatment experiment, treatment conditions, transgenic lines treated and number of in vitro rooted plants cultivated in greenhouse

\begin{tabular}{|c|c|c|c|}
\hline $\begin{array}{l}\text { Heat shock } \\
\text { experiment }\end{array}$ & Treatment conditions & Transgenic lines treated & $\begin{array}{l}\text { Rooted plants phenotyped } \\
\text { in greenhouse }\end{array}$ \\
\hline 1 & $42^{\circ} \mathrm{C}$ for 16 to 24 hours & $\begin{array}{c}\text { N82-2, N82-3, N82-4, N82-5, N82-7, N82-10, N82-11, N82-12, } \\
\text { N82-14, N82-15 }\end{array}$ & 7,856 \\
\hline 2 & $42^{\circ} \mathrm{C}$ for 24 hours & $\begin{array}{c}\text { Esch } 5 \text { (control), N 92-1, N 92-2, N 92-3, N 92-4, N 95-1, N 95- } \\
\text { 2, N 95-3, N 95-4, N 95-5, N 95-6 }\end{array}$ & 623 \\
\hline 3 & $\begin{array}{l}\text { Three days at } 42^{\circ} \mathrm{C} \text { for } 8 \text { hours, } \\
\text { recovering over night }\end{array}$ & N82-2, N82-5, N82-7, N82-11, N82-14, N82-15 & 1,587 \\
\hline \multirow[t]{2}{*}{4} & $42^{\circ} \mathrm{C}$ for 24 hours & $\begin{array}{c}\text { N 92-1, N 92-2, N 92-3, N 92-4, N 92-5, N 92-6, N95-1, N 95-2, } \\
\text { N 95-3, N 95-4, N 95-5, N 95-6 }\end{array}$ & 2,017 \\
\hline & & & 12,083 \\
\hline
\end{tabular}




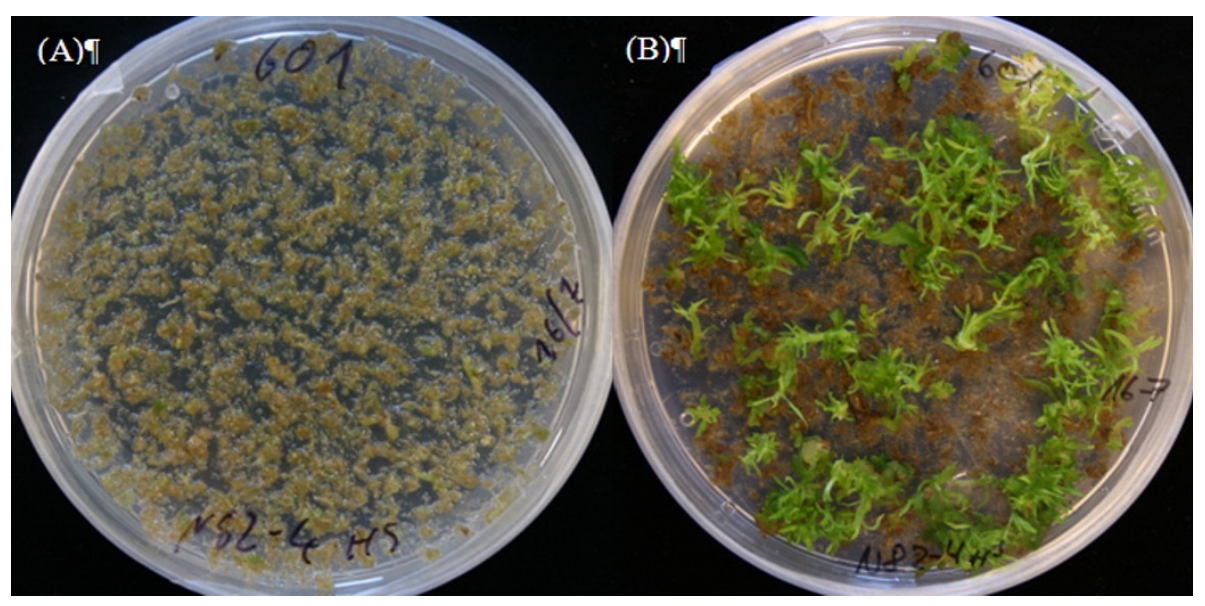

Figure 2 Following heat shock treatment, regenerative callus, leaves and stems were crushed into pieces as small as possible in a Waring blender. (A) The resulting "cell-pulp" was transferred to petridishes containing fresh regeneration medium and cultivated for up to 5 months at $25^{\circ} \mathrm{C}$ and continuous light in the growth chamber. (B) Regenerated shoots.

excised. This gene construct was transformed into two already transgenic TRANSPOSASE-expressing aspenPopulus lines. A gain-of-function rather than a loss-offunction strategy was used as this approach does not disrupt gene expression, avoids issues of gene redundancy and allows screening to occur in a primary generation. In earlier work, an "Activation tagging" approach has been recommended as particularly practicable for application in long-living trees $[13,22]$.

To date, successful T-DNA-based activation tagging mutagenesis in trees has been reported only for poplar $[14,15]$ and GA2-OXIDASE, a gibberellin catabolism gene, was the first tree gene that was isolated from a poplar T-DNA insertion population comprising 627 individuals [22]. In the following years, other T-DNA activation tagging poplar populations were produced and screened for developmental abnormalities including alterations in leaf and stem structure as well as overall stature by Harrison et al. [21] The mutant frequency reported for the largest activation tagging poplar population (with 1,800 independent transgenic lines) was about $2.4 \%$. In contrast, in our study, a total of 12,083 individuals were produced and screened, but our visible mutant frequency (containing also leaf and stem phenotypic alterations) was only $0.24 \%$. However, in an additional "blind" approach (without any previous phenotyping), we determined a frequency of $32 \%$ of ATDs transpositions in randomly selected heat shocked plants. Thus, by considering only positive ATDs-tested (transposed) individuals, the mutant frequency could be raised to approximately $1 \%$. At present, we are working on a further increase of the mutant frequency by using a positive reporter gene system combined with the ATDs system. This system only allows shoots to regenerate when the reporter gene is not active any more and thus ATDs is excised.

Thus, critically to our heat shock-based TRANSPO$S A S E$-induction strategy, the heat shock regime itself seems to influence ATDs excision rate. This is consistent with observations made in a carefully performed study on flowering response following heat shock induction of the $F T$ gene controlled also by the soybean Gmhsp17.5-E heat shock promoter, in which both the size of the treated plants as well as the temperature regime influenced success of flower induction [33]. Daily heat treatments (1-2 hours at $37^{\circ} \mathrm{C}$ ) over a period of three weeks or heat treatments of shorter durations but with increased inductive temperature (from $37^{\circ} \mathrm{C}$ to $40^{\circ} \mathrm{C}$ ) were reported to be successful for efficient flower induction in greenhouse grown plants taller than $30 \mathrm{~cm}$ [33]. In a previous study on the induction of a FLP/FRT recombination system, the soybean heat shock promoter was induced after incubation of in vitro grown transgenic poplar plants and regenerative calli at $42^{\circ} \mathrm{C}$ for 3 hours [34]. Transposase induction following heat treatment of in vitro grown individuals from double transgenic lines was also confirmed by RT-PCR (data not shown).

Possible explanations for the overall relatively low frequency of ATDs transposition could be silencing effects due to double insertion of the ATDs element or chromosomal position of the original (donor) ATDs locus. Early evidence for a relationship between T-DNA copy number and repeat formation as well as promoter methylation in poplar has been provided by Kumar and Fladung [35]. However, among the 23 different double transgenic lines carrying one to four copies of ATDs, no notable correlation was found between copy number and mutant frequency. 
Table 4 Pronounced phenotypes of ATDs tagged poplar lines: annotation results of new ATDs flanking sequences.

\begin{tabular}{|c|c|c|c|c|c|c|c|c|}
\hline $\begin{array}{l}\text { Transgenic } \\
\text { line }\end{array}$ & $\begin{array}{c}\text { Number } \\
\text { of } \\
\text { variants }\end{array}$ & $\begin{array}{c}\text { Variant } \\
\text { affiliation }\end{array}$ & Phenotype & $\begin{array}{l}\text { Genomic insertion } \\
\text { locus (scaffold: } \\
\text { position)* }\end{array}$ & Score & E-value & $\begin{array}{l}\text { Transcript } \\
\text { (POPTR_) }\end{array}$ & Functional annotation \\
\hline & & N82-2-11 & Variegated leaf & n.d.* & & & & \\
\hline & & N82-2-13 & Variegated leaf & $18: 5,952,981$ & 154.6 & $1.5 \mathrm{e}-35$ & & \\
\hline \multirow[t]{4}{*}{ N82-2 } & 5 & N82-2-14 & $\begin{array}{c}\text { Dwarf plant, weakly } \\
\text { shriveled leaf }\end{array}$ & $18: 5,946,821$ & 253.8 & $3.6 \mathrm{e}-66$ & $0018 s 06220$ & $\begin{array}{l}\text { 20G-Fe(II) oxygenase } \\
\text { superfamily }\end{array}$ \\
\hline & & N82-2-64 & Shriveled leaf & $1599: 3,445$ & 250.2 & $3.8 \mathrm{e}-65$ & & \\
\hline & & N82-2-70 & Wavy leaf & $3: 15,139,843$ & 702.8 & 0 & $0003 s 15320$ & $\begin{array}{l}\text { Hypothetical protein (basic } \\
\text { region leucine zipper) }\end{array}$ \\
\hline & & N82-3-23 & Serrated leaf & $10: 20,130,280$ & 206.9 & $5.7 e-52$ & 0010 s23600 & $\begin{array}{c}\text { 1,4-alpha-glucan branching } \\
\text { enzyme/starch branching } \\
\text { enzyme ॥ }\end{array}$ \\
\hline \multirow[t]{4}{*}{ N82-3 } & 3 & N82-3-37 & Serrated leaf & $18: 8,430,672$ or & 1063.5 & 0 & $0018 s 07730$ & $\begin{array}{l}\text { No functional annotation for } \\
\text { this gene }\end{array}$ \\
\hline & & & & $15: 1,812,282$ & 1059.9 & 0 & $0015 s 02530$ & Myosin VII \\
\hline & & N82-3-66 & Shriveled leaf & $7: 3,447,049$ & 311.5 & $9.1 e-83$ & $0007 s 05350$ & $\begin{array}{l}\text { Histone binding protein } \\
\text { RBBP4 }\end{array}$ \\
\hline & & N82-5-3 & Lanceolated leaf & $14: 11,531,333$ & 450.3 & $1.6 \mathrm{e}-124$ & & \\
\hline \multirow[t]{3}{*}{ N82-5 } & 4 & N82-5-20 & Necrotic leaf & $14: 2,480,856$ & 302.4 & $9.4 \mathrm{e}-81$ & & \\
\hline & & N82-5-26 & Bonsai plant & n.d.* & & & & \\
\hline & & N82-5-28 & Bonsai plant & $607: 2,304$ & 448.5 & $3.7 e-124$ & 0607500200 & $\begin{array}{c}\text { No functional annotation for } \\
\text { this gene }\end{array}$ \\
\hline \multirow[t]{2}{*}{ N82-7 } & 1 & N82-7-1 & Shriveled leaf & $11: 13,627,432$ & 565.7 & $1.7 e-159$ & $0011 s 10950$ & $\begin{array}{l}\text { Protein of unknown function } \\
\text { (DUF_B2219) }\end{array}$ \\
\hline & & N82-11-1 & $\begin{array}{c}\text { Crippled growth in } \\
\text { vitro, saw toothed } \\
\text { leaf }\end{array}$ & $16: 3,641,919$ & 280.8 & $1.5 e-73$ & $0016 s 05700$ & $\begin{array}{c}\text { Zinc ion binding; nucleic acid } \\
\text { binding }\end{array}$ \\
\hline \multirow[t]{6}{*}{ N82-11 } & 3 & N82-11-4 & Pale green leaf & n.d.* & & & & \\
\hline & & N82-11-5 & Pale green leaf & $16: 13,607,077$ & 426.9 & $1.4 \mathrm{e}-117$ & $0016 s 14360$ & EF-P Elongation factor \\
\hline & & N82-14-2 & Lanceolated leaf & $4: 23,008,963$ or & 780.3 & 0 & $0004 s 24320$ & $\begin{array}{c}\text { Protein of unknown function } \\
\text { (DUF1218) }\end{array}$ \\
\hline & & & & $17: 944,412$ & 1115.8 & 0 & $0017 s 01360$ & Apoptotic ATPase \\
\hline & & N82-14-3 & Shriveled leaf & $14: 6,540,903$ & 904.8 & 0 & 0014508850 & $\begin{array}{c}\text { Glycosyl hydrolases family 18; } \\
\text { Pt-CHI3.5 }\end{array}$ \\
\hline & & N82-14-4 & Weakly serrated leaf & $11: 1,379,364$ or & 535.1 & $1.2 \mathrm{e}-150$ & & \\
\hline \multirow[t]{6}{*}{ N82-14 } & 7 & & & $3: 13,395,264$ & 1079.7 & 0 & $0003 s 12970$ & $\begin{array}{l}\text { No functional annotation for } \\
\text { this gene }\end{array}$ \\
\hline & & N82-14-5 & Shriveled leaf & $10: 14,732,583$ & 892.2 & 0 & 0010s15550 & $\begin{array}{l}\text { No functional annotation for } \\
\text { this gene }\end{array}$ \\
\hline & & N82-14-6 & $\begin{array}{l}\text { Weakly shriveled } \\
\text { leaf }\end{array}$ & $2: 13,782,413$ & 298.8 & 1.1e-79 & & \\
\hline & & N82-14-9 & Shriveled leaf & $14: 10,351,781$ & 1090.5 & 0 & $0014 s 14140$ & $\begin{array}{c}\text { Protein of unknown function } \\
\text { (DUF3754) }\end{array}$ \\
\hline & & $\begin{array}{l}\text { N82-14- } \\
10\end{array}$ & Undulating leaf & $17: 1,256,405$ & 1204.1 & 0 & & \\
\hline & & N82-15-6 & Bushy plant & $4: 9,615,348$ & 1577.4 & 0 & $0004 s 11010$ & $\begin{array}{l}\text { Pentatricopeptide repeat- } \\
\text { containing protein }\end{array}$ \\
\hline \multirow[t]{2}{*}{ N82-15 } & 2 & $\begin{array}{c}\text { N82-15- } \\
10\end{array}$ & Lanceolate, serrated & $17: 2,279,602$ or & 226.7 & $5.9 e-58$ & $0017 s 03150$ & $\begin{array}{c}\text { No functional annotation for } \\
\text { this locus }\end{array}$ \\
\hline & & & leaf & $14: 14,660,942$ & 226.7 & $5.2 \mathrm{e}-58$ & & \\
\hline N92-1 & 2 & N92-1-1 & Variegated leaf & $10: 15,124,072$ & 147.4 & $6.0 e-34$ & $0010 s 16070$ & $\begin{array}{c}\text { Stress responsive A/B Barrel } \\
\text { Domain }\end{array}$ \\
\hline
\end{tabular}


Table 4 Pronounced phenotypes of ATDs tagged poplar lines: annotation results of new ATDs flanking sequences. (Continued)

\begin{tabular}{cccccc}
\hline & N92-1-6 & Variegated leaf & $10: 15,114,170$ & 206.9 & 1.2 e-51 \\
\hline N95-1 & 1 & N95-1-1 & Variegated leaf & n.d. ${ }^{*}$ & \\
\hline N95-3 & 1 & N95-3-1 & Variegated leaf & n.d. $^{*}$ & \\
\hline
\end{tabular}

Genomic insertion locus (scaffold and position) with score, e-value and, if applicable, annotated transcript.

In BLAST-analyses where more than one hit was given, either the one with lower e-value or when similar both hits are shown.

${ }^{*}$ n.d. $=$ not determined.

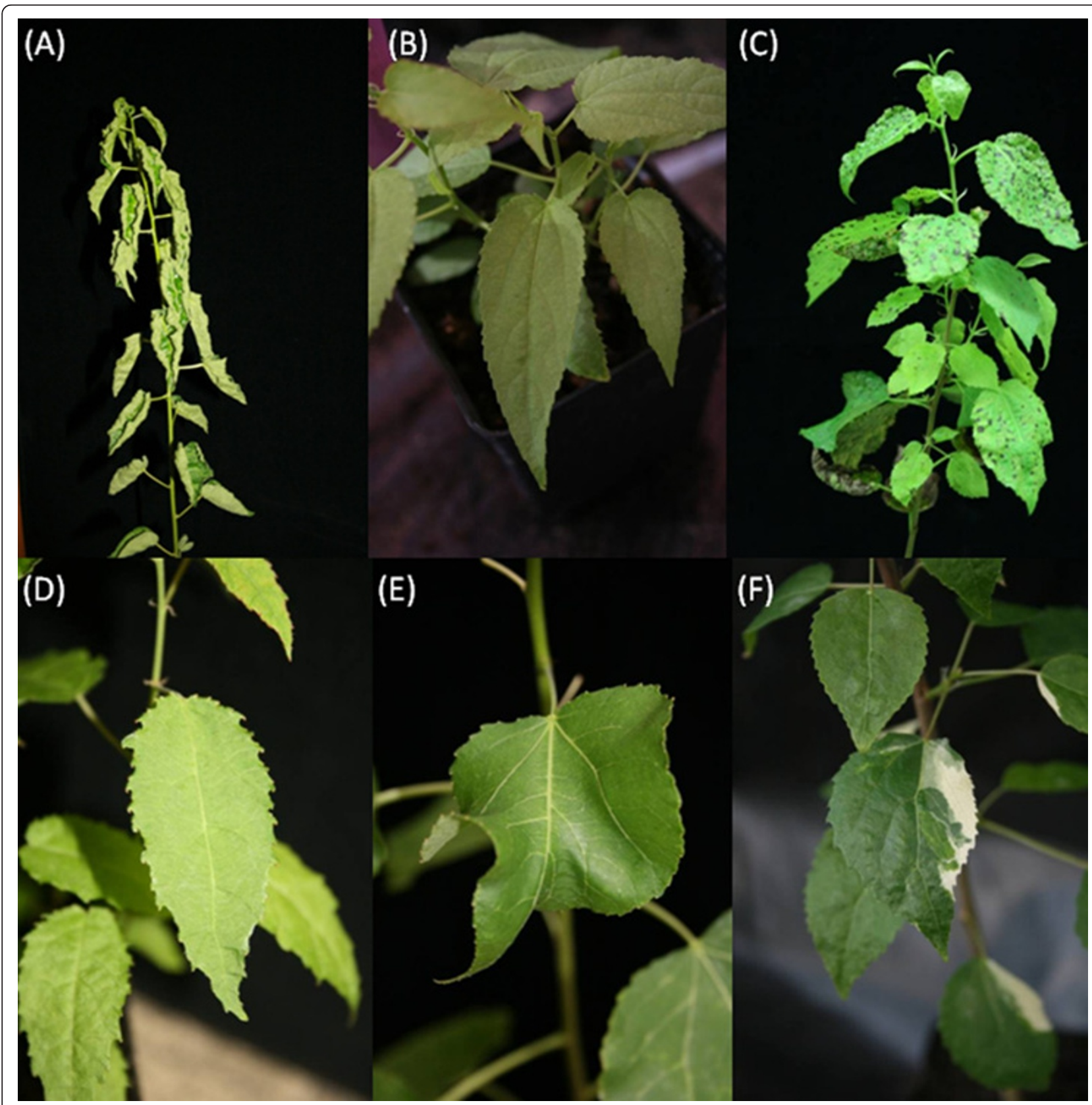

Figure 3 Examples of pronounced phenotypes of ATDs tagged poplar lines. (A) N82-3-66 (shriveled leaf), (B) N82-5-3 (lanceolated leaf), (C) N82-5-20 (necrotic leaf), (D) N82-11-1 (crippled growth in vitro, saw toothed leaf), (E) N82-14-10 (undulating leaf), (F) N92-1-6 (variegated leaf). 


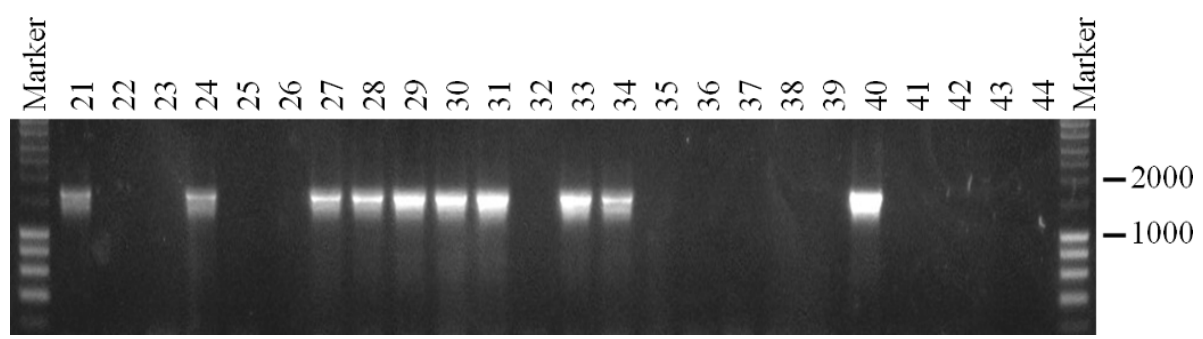

Figure 4 PCR analysis using the 16/37 primer pair (see Material and Methods) of randomly selected greenhouse-grown plants from different heat shocked double transgenic HSP::TRANSPOSASE/ATDs aspen lines. Following successful excision of ATDs a fragment of 1800 bp in size was obtained. $M=$ Marker (Smart-Ladder; Eurogentec).

Alternatively, in ten (N82-3, -4, -5, -7, -8, -10,-11, N92-3, N95-2, -3) out of 23 primary double transgenic, non-ATDs transposed lines, annotations of the ATDs donor locus flanking genomic sequences revealed insertion into or nearby genes. These ten lines, which themselves can be considered as T-DNA tagged variants, yielded only twelve ATDs-tagged variants. On the contrary, analysis of genomic sequences flanking ATDs donor loci in the two lines with the highest number of phenotypically tagged lines (N82-2 with 5 and N82-14 with 7) revealed no transcript annotation. A similar trend was observed in our anonymous approach. Here, randomly selected heat-shocked plants were first PCRscreened for successful ATDs excision, and, in a second step, ATDs excision-positive plants were analyzed for genomic localization of new ATDs insertion sites. Out of 128 tested plants from six of the above mentioned ten lines with annotations, 30 positive ATDs excisions (23.4\%) and 7 BLAST hits (5.5\%) were detected. However, three lines without any positive annotation of the ATDs donor locus flanking genomic sequences (N82-14, -15 , N92-1) revealed 34 positive ATDs excisions (59.6\%) and 16 BLAST hits (20.2\%) in 57 tested plants.

The variations in phenotype in some of the ATDstagged mutants might be similar to those observed by Harrison [36] explaining partial silencing of the shriveled leaf mutant due to methylation effects. A positive correlation between $35 \mathrm{~S}$ enhancer element methylation and

Table 5 Heat-shocked and regenerated plants from different HSP::TRANSPOSASE/ATDs double transgenic aspen lines without any phenotypic alterations (anonymous approach) grown in the greenhouse were randomly selected and tested for ATDs transposition with the primer pair 16/37.

\begin{tabular}{|c|c|c|c|c|}
\hline Transgenic line & Tested plants & PCR-positive (16/37) (\%) & TAIL-PCR and positive BLAST hits & Transcript annotation \\
\hline N82-2 & 22 & 3 & 0 & - \\
\hline N82-5 & 26 & 11 & 5 & 3 \\
\hline N82-7 & 24 & 4 & 0 & - \\
\hline N82-11 & 20 & 4 & 1 & 0 \\
\hline N82-14 & 13 & 4 & 2 & 0 \\
\hline N82-15 & 25 & 14 & 8 & 6 \\
\hline N92-1 & 19 & 16 & 6 & 4 \\
\hline N92-2 & 19 & 10 & 0 & - \\
\hline N92-3 & 20 & 0 & 0 & - \\
\hline N92-4 & 10 & 6 & 1 & 0 \\
\hline N95-1 & 23 & 2 & 0 & - \\
\hline N95-2 & 19 & 2 & 0 & - \\
\hline N95-3 & 19 & 9 & 1 & 1 \\
\hline N95-4 & 10 & 0 & 0 & - \\
\hline N95-5 & 10 & 0 & 0 & - \\
\hline N95-6 & 21 & 10 & 2 & 1 \\
\hline SUM (\%) & 300 & 95 (32\%) & $26(8.7 \%)$ & $15(5.0 \%)$ \\
\hline
\end{tabular}

Positive candidates were subjected to TAIL-PCR and sequencing to determine the new ATDs genomic insertion locus. Obtained sequences were blasted against the publicly available genome sequence of $P$. trichocarpa v2.0 (Phytozome v7.0; http://www.phytozome.net/poplar). Numbers of positive BLAST hits and, if applicable, of transcript annotations are given.

In bold the three lines with highest numbers of positive ATDs transposition and BLAST hits. 
Table 6 Annotation results of new ATDs flanking sequences in heat-shocked plants from different HSP::TRANSPOSASE/ ATDs double transgenic aspen lines without any phenotypic alterations ("blind" approach) grown in the greenhouse.

\begin{tabular}{|c|c|c|c|c|c|c|c|}
\hline $\begin{array}{l}\text { Transgenic } \\
\text { line }\end{array}$ & $\begin{array}{l}\text { Number of } \\
\text { plants }\end{array}$ & $\begin{array}{c}\text { Plant } \\
\text { affiliation }\end{array}$ & $\begin{array}{l}\text { Genomic insertion locus } \\
\text { (scaffold:position)* }\end{array}$ & Score & E-value & $\begin{array}{l}\text { Transcript } \\
\text { (POPTR_) }\end{array}$ & Functional annotation \\
\hline & & $\# 82$ & $16: 6,171,964$ & 41.0 & $5.7 e-2$ & & \\
\hline & & \# 147 & $8: 7,052,973$ & 248.3 & $1.1 \mathrm{e}-64$ & & \\
\hline \multirow[t]{3}{*}{ N82-5 } & 5 & $\# 210$ & 9:11,936,320 & 114.9 & $1.1 \mathrm{e}-23$ & $0009 s 15430$ & Carotiniod oxygenase \\
\hline & & \# 211 & $607: 7,883$ & 160.0 & $3.2 \mathrm{e}-37$ & 0607s00230 & No functional annotations for this locus \\
\hline & & \# 213 & $7: 1,458,117$ & 42.8 & $3.52 \mathrm{e}-3$ & $0007 s 02460$ & Ubiquitin-like protein \\
\hline N82-11 & 1 & \# 224 & $15: 11,529,160$ & 1103.1 & 0 & & \\
\hline \multirow[t]{6}{*}{ N82-14 } & 2 & $\# 6$ & $5: 23,009,323$ & 482.8 & $7.9 e-135$ & & \\
\hline & & \# 76 & $16: 13,632,466$ & 452.1 & $9.8 \mathrm{e}-126$ & & \\
\hline & & $\# 4$ & $2: 10,051,122$ & 42.8 & $1.6 \mathrm{e}-2$ & & \\
\hline & & \# 73 & $12: 3,471,598$ & 488.2 & $2.1 \mathrm{e}-136$ & $0012 s 04240$ & ABC-2 type transporter \\
\hline & & $\# 28$ & $19: 12,716,418$ & 223.1 & $1.3 e-56$ & 0019s11440 & Protein of unknown function (DUF803) \\
\hline & & $\# 110$ & $4: 21,317,871$ & 1402.5 & 0 & $0004 s 22400$ & $\begin{array}{l}\text { UDP-glucuronosyl and UDP-glucosyl } \\
\text { transferase }\end{array}$ \\
\hline \multirow[t]{7}{*}{ N82-15 } & 8 & $\# 131$ & $7: 13,340,488$ & 389.0 & $8.8 \mathrm{e}-107$ & $0007 s 13230$ & $\begin{array}{l}\text { Dolichyl pyrophosphate phosphatase and } \\
\text { related acid phosphatases }\end{array}$ \\
\hline & & \# 137 & $2: 10,620,751$ and & 729.8 & 0 & & \\
\hline & & & $2: 10,621,198$ & 268.2 & $1.8 \mathrm{e}-70$ & $0002 s 14350$ & PHD-finger \\
\hline & & \# 138 & $20: 865,030$ & 91.5 & $2.4 \mathrm{e}-17$ & & \\
\hline & & \# 140 & $2: 21,231,185$ & 524.3 & $2.1 \mathrm{e}-147$ & $0002 s 23690$ & Cysteine protease inhibitor activity \\
\hline & & \# 29 & $4: 1,137,737$ & 771.3 & 0 & $0004 s 01860$ & Cytochrome P450 CYP2 subfamily \\
\hline & & $\# 85$ & $10: 16,307,759$ & 787.6 & 0 & 0010 s17860 & Phosphoglycerate kinase [EC:2.7.2.3 ] \\
\hline \multirow[t]{4}{*}{ N92-1 } & 6 & \# 151 & $17: 141,236$ & 194.2 & $2.8 \mathrm{e}-48$ & $0017 s 00430$ & Serine/threonine protein kinase \\
\hline & & $\# 155$ & $8: 6,405,007$ & 403.4 & $5.0 e-111$ & & \\
\hline & & $\# 242$ & $10: 13,783,139$ & 987.7 & 0 & $0010 s 14080$ & Diaphanous homolog 2 \\
\hline & & \# 244 & $4: 17,605,886$ & 735.3 & 0 & & \\
\hline N92-4 & 1 & $\# 93$ & $10: 13,739,252$ & 336.7 & $6 ., 3 e-91$ & & \\
\hline N95-3 & 1 & \# 179 & $9: 9,182,685$ & 253.8 & $4.2 e-66$ & 0009 s10820 & $\begin{array}{c}\text { Apoptosis-promoting RNA-binding } \\
\text { protein TIA-1/TIAR }\end{array}$ \\
\hline \multirow[t]{2}{*}{ N95-6 } & 2 & \# 176 & $1: 42,827,910$ & 740.7 & 0 & & \\
\hline & & \# 190 & $1: 2,422,398$ & 459.3 & $8.0 \mathrm{e}-128$ & $0001 s 03080$ & Type II intron maturase \\
\hline
\end{tabular}

Genomic insertion locus (scaffold and position) with score, e-value and, if applicable, annotated transcript.

In BLAST-analyses with more than one hit the one with lower e-value is shown.

low frequency of T-DNA-based activation tagging was reported by Chalfun-Junior et al. [37] Further, an early report describes the influence of endogenous and environmental factors on 35S promoter methylation [38]. Because ATDs is carrying both the four repeats of enhancer elements as well two $35 \mathrm{~S}$ promoters, variations of mutant phenotypes are possible. Further, to confirm that the variants obtained are truly transposon-tagged and possibly also to explain observed phenotype variations, we already have initiated heat-shock treatments of some variants to restore the wildtype phenotype. Further, semi-quantitative PCR analyses are underway to confirm the activation of the transcripts in the variant lines.
Tagging approaches based on T-DNA insertion are effective only for plant species (like Arabidopsis and poplar) that can be easily transformed and for which high frequencies of tagged lines can be obtained [28]. One possible advantage of T-DNA based activation tagging could be that even T-DNA insertion sites are not randomly distributed in the genome but do show some insertion site preferences to the 5'UTR of a gene coding region [39]. For transposable elements, however, new insertion sites were found scattered throughout the genome at many unlinked sites $[28,31,40]$. But similar to results obtained for poplar [25], also for Arabidopsis a preferential transposon insertion around transposon donor sites was found by Raina et al. [41] However, in 
many of the heat shocked ATDs-excision positive tested plants analyzed in this study, the scaffolds revealing the new ATDs insertion loci are unlinked to those harbouring the original donor locus.

\section{Conclusions}

The fact that a transposon is able to jump to other chromosomes, thus passing chromosomal boundaries, leads to the convenient situation that only a few primary transposon transgenic lines are required for the establishment of large transposon tagging populations in order to tag at least theoretically every gene in a tree genome. This would be difficult to achieve through TDNA tagging as plant transformation is time consuming and, therefore, the genome can't easily be saturated with T-DNA tags.

For both T-DNA and transposon activation tagging, the strategy followed so far was to first phenotype an existing tagging population and then to determine new genomic insertion loci of a tag. Based on our results presented here, we propose a novel strategy of activation tagging that is supported by the demonstrated power of the ATDs transposon approach and the simplicity to induce ATDs transposition in vitro at least in some lines. The ATDs-based strategy allows first the production of a very high number of independent ATDs-transposed plants that can be screened for new ATDs flanking genomic loci. The sequences obtained in this way can then be subjected to BLAST analyses, and finally based on this in silico research, variants of specific interest can be selected, transferred to and investigated in the greenhouse.

\section{Methods}

\section{Plasmids}

Two constructs formed the basis for our experiments. The first construct, p6-HSP-TP-OCS, carries the TRANSPOSASE gene from the Ac element from maize under control of the soybean heat shock promoter (HSP) Gmhsp17.5-E [42] and is similar to the heatshock inducible transposase system described by Czarnecka et al [43] (Figure 5a). As plant selectable marker this construct carries the hygromycin resistance gene (hpt) under control of the cauliflower mosaic virus (CaMV) 35S promoter.

The second construct, p7N-ATDs-rolC (Figure 5b), comprises the "Activation Tagging Ds" system (ATDs) kindly provided by Y. Suzuki, University of Tokyo, Tokyo Japan [26] and the rolC gene from Agrobacterium rhizogenes which functions as phenotypic selectable marker $([23,24]$ for transposition of the ATDs (Figure $5 \mathrm{~b})$. The ATDs is flanked by terminal inverted repeats and contains two CaMV 35S promoters facing outward as well as four tandem repeats of enhancer fragments

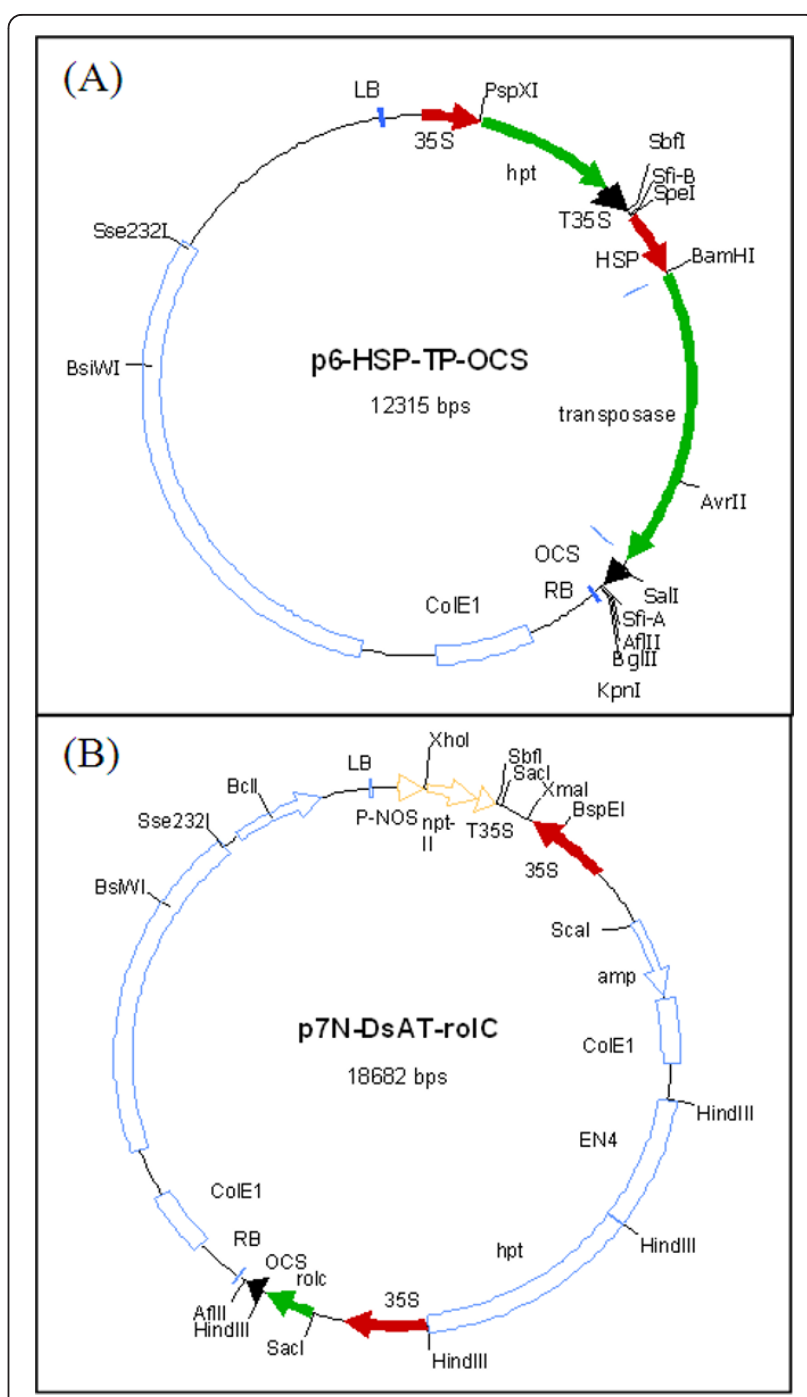

Figure 5 Schematic representation of the binary vectors p6-HSPTP-OCS (A) and p7N-ATDs-rolC (B) used for the transformation experiments. (A) Structure of the plasmid containing the $A C$ transposase and heat shock promoter (HSP) Gmhsp17.5-E from soybean [42], and hpt as plant selectable marker. (B) Structure of the activation construct (ATDs) [26]. The ATDs contains hpt as transposition selection marker. The rolC gene is outside of ATDs and the CaMV 355 promoter on the left site of the ATDs keeps this gene active under non-excised stage. The nptll gene with the nopaline synthase promoter (nos) is used as transformation marker. Relevant restriction enzyme cutting sites are introduced into the maps. (P-NOS = Nopaline synthase promoter; HSP = GmHSP 17.5-E promoter; nptll = neomycin phosphotransferase gene; hpt = hygromycin phosphotransferase gene; 35S = CaMV35S promoter; T35S = CaMV35S terminator; OCS = Octopine synthase gene terminator; EN4 = four tandem repeats of enhancer fragments; rolC = rolC gene from Agrobacterium rhizogenes; $\mathrm{LB}$ and $\mathrm{RB}=$ Left- and right border sequences).

(En) of the 35S promoter that work for promoter-type and enhancer-type gene activation, respectively. The rolC marker gene is located outside of the ATDs element, and following excision of ATDs, rolC becomes 
promoterless und thus inactive. For selection of transgenic plants the ATDs construct carries the nptII selectable marker gene.

Both gene constructs were transferred into the Agrobacterium tumefaciens strain GV3101::pMP90RK [44].

Transformation of aspen with the TRANSPOSASE gene and selection of two transgenic lines for super-transformation The aspen hybrid clone "Esch5" (P. tremula L. $\times$ P. tremuloides Michx.) was first transformed with p6-HSP-TPOCS carrying the TRANSPOSASE gene using a Agrobacterium-mediated leaf disc co-cultivation method as described by Fladung et al [45] and Hoenicka et al. [46] For selection of transgenic plants, the regeneration media contained hygromycin $(20 \mathrm{mg} / \mathrm{L})$ and Cefotaxime $(500$ $\mathrm{mg} / \mathrm{L})$. In total, seven independent transgenic lines tested positive for presence of a HSP-TRANSPOSASE fragment in PCR experiments (data not shown). Further, a RTPCR approach was followed to assess transposase transcription in the seven HSP-TRANSPOSASE transgenic lines following a $24 \mathrm{~h}$ culture at $37^{\circ} \mathrm{C}$ under continuous light. Induction of transposase transcription was observed in all investigated HSP-TRANSPOSASE transgenic lines, thus, this treatment was sufficient to induce the transposase without inflicting noticeable stress on the plants (data not shown). In order to show that transposase transcription did not occur in non-heat-shock-treated plants (due to theoretically possible leakage of the HSP promoter), non-induced leaves were included in RT-PCR experiments, and no such transcription was detected (data not shown). Finally, four weeks after heat-shock treatments RNA was again isolated from leaves of two HSP-TRANSPOSASE transgenic lines and RT-PCR experiments were performed, confirming that four weeks after treatment transposase transcripts are no longer detectable (data not shown). Based on these results, two independent transgenic lines, N66-2 and N66-5, were chosen for super-transformation with ATDs.

\section{Super-transformation of N66-2 and N66-5 with p7N-ATDs- rolc}

For the two independent TRANSPOSASE-transgenic aspen lines N66-2 and N66-5, an Agrobacteriummediated super-transformation with the p7N-ATDs-rolC construct (carrying the ATDs element) was performed. In total, 13 and twelve independent double transgenic lines were obtained for N66-2 and N66-5, respectively, and analysed in PCR experiments for presence of this second gene construct (data not shown). Complete integration of this gene construct was tested using primer pairs that cover the region from the 35S-promoter of the ATDs element to flanking genes (either rolC [at right border of T-DNA] or nptII [at left border of TDNA], see Figure 5b). For 23 transgenic lines complete integration of the ATDs construct was confirmed (twelve lines for N66-2 and eleven lines for N66-5) (data not shown). Affiliations of the p7N-ATDs-rolC-transgenic lines for N66-2 are: N82-2, N82-3, N82-4, N82-5, N82-7, N82-8, N82-10, N82-11, N82-12, N82-13, N8214 , N82-15, and for N66-5: N92-1, N92-2, N92-3, N924, N92-6, N95-1, N95-2, N95-3, N95-4, N95-5, N95-6. These lines were considered for the activation tagging experiments described below.

\section{DNA extraction, PCR confirming ATDs excision, and Southern blot analyses}

Genomic DNA was isolated from transgenic aspen lines using the $C T A B$ method described by Dumolin-Lapègue et al [47], and total RNA was purified according to Logemann et al [48]. DNase-treatment of purified RNA was done with RNAfree DNAse (Cat. Nr. M6101, Promega, Mannheim, Germany) followed by transposase transcription using the Access RT-PCR System (Cat. Nr. A1250, Promega, Mannheim, Germany).

Excision of the ATDs fragment after heat shock treatment was verified by PCR using the primer pair nptII (forward [F]; internal primer number \#16, 5'-ATG GAT TGC ACG CAG GTT CTC-3') and rolC (reverse [R]; internal primer number \#37; 5'-AAC TCA CCA GGT TCG AAC CTA-3'). Following successful excision of ATDs, a fragment of $1800 \mathrm{bp}$ in size was obtained.

Copy numbers of the TRANSPOSASE and ATDs constructs were determined by Southern blot analyses using DIG-labelled DNA-probes specific for TRANSPOSASE and hpt (for N66-2 and N66-5), and nptII and rolC (for eleven N82er-, five N92er-, and six N95er transgenic lines).

For Southern blot analyses, $20 \mu \mathrm{g}$ of genomic DNA was cleaved with BamHI (N66-2, N66-5), and ScaI or SacI (for N82er-, N92er-, and N95er transgenic lines). Restricted DNA samples were separated on 1.3 or $1.5 \%$ agarose gels in TAE buffer, blotted on nylon membranes and hybridised with DIG-labelled DNA probes as described by Fladung et al [45]. DIG-labelling of all DNA-probes was done in a PCR reaction according to Fladung and Ahuja [24] using the following primer pairs: TRANSPOSASE (F; \#1: 5'-AAT AAG TCA TAC ATG TGT GTC ACC-3'/R; \#2: 5'-TAC AAT TTT CTA ATG ACC CTA ACA-3'); hpt (F; \#337: 5'-AAA GCC TGA ACT CAC CGC GA-3'/R; \#338:5'-TCG GTT TCC ACT ATC GGC GA-3') nptII (F; \#16: 5'-ATG GAT TGC ACG CAG GTT CTC-3'/R; \#17: 5’-AAG GCG ATA GAA GGC GAT GCG-3') rolC (F; \#6: 5'-GGC TGA AGA CGA CCT GTG TTC TCT-3'/R; \#37: 5'AAC TCA CCA GGT TCG AAC CTA-3').

TAIL-PCR for determination of genomic integration sites TAIL-PCR was performed as described by Liu et al [49] with the following modifications. Annealing 
temperatures during PCR reactions in TAIL1, TAIL2 and TAIL3 were adapted to the requirements of the specific primer used. For TAIL1, 200 ng of genomic DNA was added to the reaction mix, and TAIL1 products were diluted 1:50 with water for TAIL2, and $1 \mu \mathrm{l}$ of TAIL2 was directly taken for TAIL3. Taq-polymerase and PCR buffer from the Expand Long Range dNTPack (Roche, Germany) were used for PCR reaction instead of standard Taq.

All three arbitrary degenerate (AD) primers were tested in combination with three specific primers designed for the left and right borders of p6-HSP-TPOCS (carrying the TRANSPOSASE gene) and p7NATDs-rolC (carrying ATDs). The 64-fold degenerate AD-primer (5'-NTC GAS TWT SGW GTT-3') was most successful in generating fragments in the three subsequent TAIL-PCR rounds in combination with the construct specific primers 1, 2, and 3 (see below). In cases where no PCR products were obtained with the 64-fold degenerate AD primer, the 128-fold (5'-NGT CGA SWG ANA WGA A-3') or even the 256-fold (5'WGT GNA GWA NCA NAG A-3') degenerate AD-primer was used for the PCR reactions.

For TAIL-PCR amplification of genomic left and right border flanking regions of the p6-HSP-TP-OCS construct (transgenic plant lines N66-2, N66-5), the following specific primers were used in combination with the AD primers: left border: primer 1: 5'-TGG GAT TGT GCG TCA TCC CT-3'; primer 2: 5'-ATC CGA GGA GGT TTC CCG-3'; primer 3: 5'-GAC GGA TCG TAA TTT GTC GTT-3'; right border: primer 1: 5'-AGG ATT ATG ATC AAG TAG AGT C-3'; primer 2: 5'-AAG ATT GGG TAG CAG CAT CTA-3'; primer 3: 5'-TCA GAT CCT TAC CGC CGG TTT-3'.

For amplification of the original genomic insertion locus of the p7N-ATDs-rolC construct the following primers were used in combination with the AD primers: left border: primer 1: 5'-AAG GCG ATA GAA GGC GAT GCG-3'; primer 2: 5'-TTC AAC GTT GCG GTT CTG TCA-3'; primer 3: 5'-GAC GGA TCG TAA TTT GTC GTT-3'; right border: primer 1: 5'-TTA TAC GAT AAC GGT CGG TAC-3'; primer -2: 5'-ACT GCC CGA CGA TGA TGC TCT-3'; primer -3: 5'-TCA GAT CCT TAC CGC CGG TTT-3'.

Following heat shock, the new genomic positions of the ATDs element were determined by using the following primers in combination with the $\mathrm{AD}$ primers: left site of ATDs: primer 1: 5'-AGT CCA AAT CGG ATC TGT AAG-3'; primer 2: 5'-ACC GAA CAA AAA TAC CGG TTC-3'; primer 3: 5'-CGA TTA CCG TAT TTA TCC CGT-3'; right site of ATDs: primer 1: 5'-TGC AGT CAT CCC GAA TTA GAA-3'; primer 2: 5'-CGT TTC CGT TTA CCG TTT TGT-3'; primer 3: 5'-TTA TAC GAT AAC GGT CGG TAC-3'.
Fragments obtained were eluted from agarose (Qiagen, Duesseldorf, Germany) and sequenced (StarSeq, Mainz, Germany). All sequences obtained were blasted against the publicly available genome sequence of $P$. trichocarpa v2.0 (Phytozome v7.0; http://www.phytozome.net/ poplar).

Successful BLAST-results were used to position the TDNA on the physical map of P. trichocarpa. These positions could be assigned to the Populus-aspen genome because of the high collinearity between the $P$. trichocarpa and P. tremula/P.tremuloides genomes [50].

All aspen-specific sequences obtained in this study were integrated into GabiPD database (http://www. gabipd.org) and submitted to GenBank ([GenBank: JM973488] to [GenBank:JM973566]).

\section{Heat shock treatments to induce ATDs transposition}

Four different heat shock experiments were conducted with 23 independent double transgenic HSP::TRANSPOSASE/ATDs aspen lines (Table 3). To activate the ATDs transposition system, transgenic regenerative callus cultures, including regenerated poplar shoots, were incubated at various temperature regimes as shown in Table 3 . Treatment conditions were either 16 or 24 hours at $42^{\circ} \mathrm{C}$ (experiments 1,2 , and 4 ) or 8 hours at $42^{\circ} \mathrm{C}$ applied over three subsequent days (experiment 3 ).

One to twenty four hours after the heat shock treatment, regenerative callus, leaves and stems were crushed into small pieces by using a Waring blender (pieces as small as possible but without destroying individual cells). The resulting "cell-pulp" was transferred to fresh regeneration medium (Figure 2) and cultivated for up to 5 months at $25^{\circ} \mathrm{C}$ under continuous light in a growth chamber. Regenerated shoots were cut and transferred to WPM medium without rooting hormones. After 4 to 8 weeks, rooted plants were phenotyped in tissue culture for the first time. Rooted plants were transferred into soil and phenotyped again after three to six months of growth in the greenhouse.

\section{Phenotyping of in vitro- and greenhouse grown plants}

Rooted plants in vitro were screened for growth deficiency and chlorophyll abnormalities. In the greenhouse, up to six-months-old plants were screened for phenotypic variations as well as for leaf form and shape alterations.

For the "blind" approach, 300 greenhouse-grown plants without any obvious phenotypic alterations were randomly selected from 16 different double transgenic HSP::TRANSPOSASE/ATDs aspen lines and PCRscreened for ATDs transposition using the 16/37 primer pair as described above. Plants that tested positive were further screened by TAIL-PCR for new genomic location of the ATDs as described above with the exception 
that a standard Taq-polymerase (DNA Cloning Service, Hamburg, Germany) was used instead of the LongRange Taq. Fragments obtained were sequenced (StarSeq, Mainz, Germany), and the sequences were blasted against the publicly available genome sequence of $P$. trichocarpa (assembly v2.0; Phytozome v7.0; http://www. phytozome.net/poplar).

\section{Acknowledgements}

This work was supported by the German Federal Ministry of Education and Research (BMBF) funded under 'Genome Analysis in the Biological System Plant' (GABl; project GABI-POP) and the German Research Foundation (projects FL263/12-2 and FL263/12-3). We thank D. Ebbinghaus and A. Schellhorn for skillful technical assistance. We also thank Y. Suzuki (University of Tokyo, Japan) for the gift of the ATDs element, and Prof. Dr. Gerd Bossinger (The University of Melbourne, Australia) for critically reading the manuscript and for his very helpful corrections. We are also very grateful to Birgit Kersten (vTI Grosshansdorf, Germany), Doreen Pahlke and Prof. Björn Usadel (both MPI for Molecular Plant Physiology, Potsdam, Germany) for data integration into GabiPD (http://www.gabipd.org) and sequence submission to GenBank.

\section{Authors' contributions}

This study was conceptualized planned by MF. All experimental work was conducted by OP, supervised by MF. The paper was written by MF. All authors have read and approved the final manuscript.

Received: 3 October 2011 Accepted: 6 February 2012

Published: 6 February 2012

\section{References}

1. Bradshaw HD Jr, Strauss SH: Breeding strategies for the 21th century: domestication of poplar. In Poplar culture in North America. Edited by: Dickmann DI, Isebrands JG, Eckenwalder JH, Richardson J. Ottawa, National Research Council of Canada: NRC Research Press; 2001:383-394.

2. Tuskan GA, Difazio S, Jansson S, Bohlmann J, Grigoriev I, Hellsten U, Putnam N, Ralph S, Rombauts S, Salamov A, Schein J, Sterck L, Aerts A, Bhalerao RR, Bhalerao RP, Blaudez D, Boerjan W, Brun A, Brunner A, Busov V, Campbell M, Carlson J, Chalot M, Chapman J, Chen GL, Cooper D, Coutinho PM, Couturier J, Covert S, Cronk Q, et al: The genome of black cottonwood, Populus trichocarpa (Torr. \& Gray). Science 2006, 313:1596-604

3. Colbert T, Till BJ, Tompa R, Reynolds S, Steine MN, Yeung AT, McCallum CM, Comai L, Henikoff S: High-throughput screening for induced point mutations. Plant Physiol 2001, 126:480-484.

4. Flachowsky H, Hanke MV, Peil A, Strauss SH, Fladung M: A review on transgenic approaches to accelerate breeding of woody plants. Plant Breeding 2009, 128:217-226.

5. Parinov S, Sundaresan V: Functional genomics in Arabidopsis: large-scale insertional mutagenesis complements the genome sequencing project. Curr Opin Biotechnol 2000, 11:157-161.

6. Pogorelko GV, Fursova OV, Ogarkova OA, Tarasov VA: A new technique for activation tagging in Arabidopsis. Gene 2008, 414:67-75.

7. Marsch-Martínez N, Pereira A: Activation tagging with En/Spm-I/dSpm transposons in Arabidopsis. Methods Mol Biol 2011, 678:91-105.

8. Marsch-Martinez N, Greco R, Van Arkel G, Herrera-Estrella L, Pereira A: Activation Tagging Using the En-I Maize Transposon System in Arabidopsis. Plant Physiol 2002, 129:1544-1556.

9. Qu S, Desai A, Wing R, Sundaresan V: A versatile transposon-based activation tag vector system for functional genomics in cereals and other monocot plants. Plant Physiol 2008, 146:189-199.

10. Hsing YI, Chern CG, Fan MJ, Lu PC, Chen KT, Lo SF, Sun PK, Ho SL, Lee KW, Wang YC, Huang WL, Ko SS, Chen S, Chen JL, Chung Cl, Lin YC, Hour AL, Wang YW, Chang YC, Tsai MW, Lin YS, Chen YC, Yen HM, Li CP, Wey CK, Tseng CS, Lai MH, Huang SC, Chen L, Yu SM: A rice gene activation/ knockout mutant resource for high throughput functional genomics. Plant Mol Biol 2007, 63:351-364.
11. Ayliffe MA, Pryor AJ: Activation tagging and insertional mutagenesis in barley. Methods Mol Biol 2011, 678:107-128.

12. Ayliffe MA, Pallotta M, Langridge P, Pryor AJ: A barley activation tagging system. Plant Mol Biol 2007, 64:329-347.

13. Fladung $M$, Deutsch F, Hönicka $H$, Kumar S: DNA and transposon tagging in aspen. Plant Biol 2004, 6:5-11.

14. Busov V, Fladung M, Groover A, Strauss SH: Insertional mutagenesis in Populus: relevance and feasibility. Tree Gen Genom 2005, 1:135-142.

15. Busov V, Yordanov Y, Gou J, Meilan R, Ma C, Regan S, Strauss S: Activation tagging is an effective gene tagging system in Populus. Tree Gen Genom 2011, 7:91-101.

16. Hayashi H, Czaja I, Lubenow H, Schell J, Walden R: Activation of a plant gene by T-DNA tagging: auxin-independent growth in vitro. Science 1992, 258:1350-1353.

17. Wilson K, Long D, Swinburne J, Coupland G: A Dissociation insertion causes a semidominant mutation that increases expression of TINY, an Arabidopsis gene related to APETALA2. Plant Cell 1996, 8:659-671.

18. Tani H, Chen X, Nurmberg P, Grant JJ, SantaMaria M, Chini A, Gilroy E, Birch PRJ, Loake GJ: Activation tagging in plants: a tool for gene discovery. Funct Integr Genom 2004, 4:258-266.

19. Weigel D, Ahn JH, Blazquez MA, Borevitz JO, Christensen SK, Fankhauser $C$, Ferrandiz C, Kardailsky I, Malancharuvil EJ, Neff MM, Nguyen JT, Sato S, Wang ZY, Xia Y, Dixon RA, Harrison MJ, Lamb CJ, Yanofsky MF, Chory J: Activation Tagging in Arabidopsis. Plant Physiol 2000, 122:1003-1013.

20. Østergaard L, Yanofsky MF: Establishing gene function by mutagenesis in Arabidopsis thaliana. Plant J 2004, 39:682-696.

21. Harrison EJ, Bush M, Plett JM, McPhee DP, Vitez R, O'Malley B, Sharma V, Bosnich W, Seguin A, MacKay J, Regan S: Diverse developmental mutants revealed in an activation tagged population of poplar. Can J Bot 2007, 85:1071-1087.

22. Busov V, Meilan R, Pearce DW, Ma C, Rood SB, Strauss SH: Activation tagging of a dominant gibberellin catabolism gene (GA 2-oxidase) from poplar that regulates tree stature. Plant Physiol 2003, 132:1283-1291.

23. Kumar S, Fladung M: Somatic mobility of the maize element Ac and its usability for gene tagging in aspen. Plant Mol Biol 2003, 51:643-650.

24. Fladung M, Ahuja MR: Excision of the maize transposable element $A c$ in periclinal chimeric leaves of 35S-Ac-ro/C transgenic aspen-Populus. Plant Mol Biol 1997, 33:1097-1103.

25. Fladung M: Analysis of re-integrated Ac element positions in the genome of Populus provides a basis for Ac/Ds-transposon activation tagging in trees. Trees 2011, 25:551-557.

26. Suzuki $Y$, Uemura S, Saito $Y$, Murofushi N, Schmitz G, Theres $K$, Yamaguchi I: A novel transposon tagging element for obtaining gain-of-function mutants based on a self-stabilizing Ac derivative. Plant Mol Biol 2001, 45:123-131.

27. Parinov S, Sevugan M, Ye D, Yang WC, Kumaran M, Sundaresan V: Analysis of flanking sequences from Dissociation insertion lines: a database for reverse genetics in Arabidopsis. Plant Cell 1999, 11:2263-2270.

28. Qu SH, Desai A, Wing R, Sundaresan V: A versatile transposon-based activation tag system for functional genomics in cereals and other monocot plants. Plant Physiol 2008, 146:189-199.

29. Qu S, Jeon JS, Ouwerkerk PB, Bellizzi M, Leach J, Ronald P, Wang GL: Construction and application of efficient Ac-Ds transposon tagging vectors in rice. J Integr Plant Biol 2009, 51:982-992.

30. Greco R, Ouwerkerk PBF, Kam RJ, De Sallaud C, Favalli C, Colombo L, Guiderdoni E, Meijer AH, Hoge JHC, Pereira A: Transpositional behaviour of an Ac/Ds system for reverse genetics in rice. Theor Appl Genet 2004, 108:10-24.

31. McKenzie N, Dale PJ: Mapping of transposable element Dissociation inserts in Brassica oleracea following plant regeneration from streptomycin selection of callus. Theor Appl Genet 2004, 109:333-341.

32. Fladung M: Gene stability in transgenic aspen (Populus). I. Flanking DNA sequences and T-DNA structure. Mol Gen Genet 1999, 260:574-581.

33. Zhang H, Harry DE, Ma C, Yuceer C, Hsu CY, Vikram V, Shevchenko O, Etherington $\mathrm{E}$, Strauss SH: Precocious flowering in trees: The FLOWERING LOCUS T gene as a research and breeding tool in Populus. J Exp Bot 2010, 61:2549-2560.

34. Fladung M, Schenk TMH, Polak O, Becker D: Elimination of marker genes and targeted integration via FLP/FRT-recombination system from yeast in hybrid aspen (Populus tremula L. $\times$ P. tremuloides Michx.). Tree Gen Genom 2010, 6:205-217. 
35. Kumar S, Fladung M: Determination of T-DNA repeat formation and promoter methylation in transgenic plants. BioTechniques 2000, 28:1128-1137.

36. Harrison EJ: Activation Tagging as a Powerful Tool for Gene Discovery in Poplar. PhD thesis Queen's University, Biology department; 2008.

37. Chalfun-Junior A, Mes JJ, Mlynarova L, Aarts MG, Angenent GC: Low frequency of T-DNA based activation tagging in Arabidopsis is correlated with methylation of CaMV 35 S enhancer sequences. FEBS Lett 2003, 555:459-463.

38. Meyer P, Linn F, Heidmann I, Meyer H, Niedenhof I, Saedler H: Endogenous and environmental factors influence $35 \mathrm{~S}$ promoter methylation of a maize A1 gene construct in transgenic petunia and its colour phenotype. Mol Gen Genet 1992, 231:345-352.

39. Pan $X, L i$ Y, Stein $L$ : Site preferences of insertional mutagenesis agents in Arabidopsis. Plant Physiol 2005, 137:168-175.

40. Kolesnik T, Szeverenyi I, Bachmann D, Kumar CS, Jiang S, Ramamoorthy R, Cai M, Ma ZG, Sundaresan V, Ramachandran S: Establishing an efficient Acl Ds tagging system in rice: large-scale analysis of Ds flanking sequences. Plant J 2004, 37:301-314.

41. Raina S, Mahalingam R, Chen FQ, Fedoroff N: A collection of sequenced and mapped Ds transposon insertion sites in Arabidopsis thaliana. Plant Mol Biol 2002, 50:93-110.

42. Czarnecka E, Gurley WB, Nagao RT, Mosquera LA, Key JL: DNA-sequence and transcript mapping of a soybean gene encoding a small heat-shock protein. Proc Natl Acad Sci USA 1985, 82:3726-3730.

43. Balcells L, Sundberg E, Coupland G: A heat-shock promoter fusion to the Ac transposase gene drives inducible transposition of a Ds element during Arabidopsis embryo development. The Plant J 1994, 5:755-764.

44. Koncz C, Schell J: The promoter of the TL- DNA gene 5 controls the tissue-specific expression of chimaeric genes carried by a novel type of Agrobacterium vector. Mol Gen Genet 1986, 204:383-96.

45. Fladung M, Kumar S, Ahuja MR: Genetic transformation of Populus genotypes with different chimeric gene constructs: Transformation efficiency and molecular analysis. Trans Res 1997, 6:111-121.

46. Hoenicka H, Nowitzki O, Hanelt D, Fladung M: Heterologous overexpression of the birch FRUITFULL-like MADS-box gene BpMADSA prevents normal senescence and winter dormancy in Populus tremula $\mathrm{L}$. Planta 2008, 227:1001-1011.

47. Dumolin-Lapègue S, Petit RJ, Gielly L, Taberlet P: Amplification of DNA from ancient and modern oak wood. Mol Ecol 1999, 8:2137-2140.

48. Logemann J, Schell J, Willmitzer L: Improved method for the isolation of RNA from plant tissues. Anal Biochem 1987, 163:16-20.

49. Liu YG, Mitsukawa N, Oosumi T, Whittier RF: Efficient isolation and mapping of Arabidopsis thaliana T-DNA insert junctions by thermal asymmetric interlaced PCR. The Plant J 1995, 8:457-463.

50. Pakull B, Groppe K, Meyer M, Markussen T, Fladung M: Genetic Linkage Mapping in Aspen (Populus tremula L. and P. tremuloides Michx.). Tree Gen Genom 2009, 5:505-515.

doi:10.1186/1471-2164-13-61

Cite this article as: Fladung and Polak: Ac/Ds-transposon activation tagging in poplar: a powerful tool for gene discovery. BMC Genomic 2012 13:61.

\section{Submit your next manuscript to BioMed Central and take full advantage of:}

- Convenient online submission

- Thorough peer review

- No space constraints or color figure charges

- Immediate publication on acceptance

- Inclusion in PubMed, CAS, Scopus and Google Scholar

- Research which is freely available for redistribution

Submit your manuscript at www.biomedcentral.com/submit
Biomed Central 